\title{
Change in overweight and obesity prevalence and adipose tissue distribution in seven-year-old Czech children (COSI project) 2008 to 2016
}

\author{
Marie Kunesova ${ }^{1}$, Radka Raxová Braunerová ${ }^{1}$, Bohuslav Procházka² ${ }^{2}$ Jana Vignerova $^{1}$, \\ Tereza Metelcova ${ }^{1,3}$, Jana Parizkova ${ }^{1}$, Martin Hill $^{1}$ and Hana Zamrazilova ${ }^{1}$ \\ ${ }^{1}$ Institute of Endocrinology Obesity Management Centre, Prague, Czech Republic, \\ ${ }^{2}$ Paediatric Clinic, Kolin, Czech Republic and \\ ${ }^{3}$ Charles University, First Faculty of Medicine, Prague, Czech Republic
}

Introduction: Adipose tissue distribution is one of the factors influencing development of cardiometabolic complications associated with overweight and obesity. Waist circumference and waist/height ratio (WHtR) are markers of central adipose tissue distribution The aim of the study was to compare overweight/obesity and adipose tissue distribution in 7 year old Czech children and change in overweight/obesity and abdominal obesity from 2008 to 2016. WHO Europe initiated surveillance of childhood obesity (Childhood Obesity Surveillance Initiative COSI) in 2007/2008 ${ }^{(1)}$.

Methods: In representative samples of 7 year old children weight, height, waist and hip circumference were measured and BMI and waist to height ratio were calculated in years 2008, 2010, 2013 and 2016. Statistical analysis was done using Statgraphics.

Results and discussion: Since 2008 we found that overweight and obesity prevalence in 7- year-old children in the Czech Republic has been stable. In boys mild shift from overweight to obesity was observed. In 2016 preobesity was found in $7.6 \%$ of boys and in $6.5 \%$ of girls, obesity in $8.8 \%$ of boys and $6.5 \%$ of girls (according to the Czech reference values). The main factors contributing to preobesity and obesity development were lower education of mother, less frequent consumption of breakfast, less frequent consumption of full milk and less time spent playing outside. Higher weight of parents, family history of obesity, higher birth weight and longer screen time were associated with higher prevalence of overweight and obesity.

Waist circumference and waist to height ratio in all children increased in period 2008-2016. WHtR $>0.5$ was suggested as a marker of abdominal adipose tissue distribution in children ${ }^{(2)}$. We evaluated percentage of children with WHtR higher than 0.5 in $2008-2016$. The difference was statistically significant. In 2016, 24 per cent of children with WHtR $>0.5$ had normal BMI. Assessment of waist and WHtR may contribute to identify children with increased health risk.

Conclusion: Overweight and obesity prevalence in Czech 7-year-old children is not increasing in last years. Waist measurement and waist to height ratio assessment are simple indicators of adipose tissue distribution in children. Further studies are necessary for evaluation of their role in childhood obesity diagnostics.

\section{Acknowledgements}

The study was supported by grants: AZV MZČR 17-31670 A and MZČR - RVO EÚ 00023761

\section{Conflict of Interest}

There is no conflict of interest

\section{References}

1. Wijnhoven T \& Branca F (2008) WHO European Childhood Obesity Surveillance Initiative. Protocol. Copenhagen: WHO Regional Office for Europe.

2. McCarthy HD \& Ashwell M (2006) Int J Obes (Lond) 30, 988-992. 